\title{
Clinical Studies
}

\section{Influence of Residual Antegrade Coronary Blood Flow on the Long-term Prognosis of Medically Treated Patients with Myocardial Infarction and Single-vessel Disease}

\author{
Hiroshi Imamura, MD, Shinichiro Nishiyama, ${ }^{\prime}$ MD, \\ Shigemoto NAKANISHI, ${ }^{1} \mathrm{MD}$, \\ and Akira SEKI, ${ }^{1} \mathrm{MD}$
}

\begin{abstract}
SUMMARY
We assessed the influence of residual antegrade coronary perfusion on long-term mortality and morbidity in 262 patients (256 men and 6 women, aged $52.3 \pm 9.8$ years) with medically treated old myocardial infarction and single-vessel disease who were followed for $117.0 \pm 39.8$ months. Partial or complete antegrade coronary perfusion of the infarct artery was present in 165 patients (group I); no or minimal antegrade perfusion of the infarct artery was present in 97 patients (group II). There was no significant difference in survival between group I (5-year survival rate, $96.9 \%$ and 10 -year survival rate, 90.7\%) and group II (93.8\% and $92.7 \%$, respectively). There was also no significant difference in the event free survival rate between group I (5-year, 92.6\% and 10 -year, $79.7 \%)$ and group II $(89.5 \%$ and $74.8 \%$, respectively). The extent of left ventricular dysfunction was an important determinant of prognosis: 10-year survival rates in patients with ejection fractions of $>60 \%, 40-60 \%$ and $<40 \%$ were $94.8 \%, 90.6 \%$ and $74.8 \%$, respectively. In the majority of patients the subsequent cardiac events werc related to the progression of atherosclerosis in previously nonstenotic coronary arteries. Thus, the presence or absence of residual antegrade coronary flow in the chronic phase of myocardial infarction did not significantly influence the long-term prognosis of patients with singlevessel disease. (Jpn Heart J 1997; 38: 27-38)
\end{abstract}

Key words: Survey, Mortality, Reperfusion therapy, Coronary artery disease, Percutaneous transluminal coronary angioplasty (PTCA), Coronary artery bypass grafting $(\mathrm{CABG})$

$\mathrm{R}$ EPERFUSION therapy restores antegrade coronary blood flow, ${ }^{1,2)}$ improves left ventricular (LV) function ${ }^{3)}$ and reduces mortality ${ }^{4)}$ in patients with acute myocardial infarction. Although most studies have suggested that

From the First Department of Internal Medicine, Shinshu University School of Medicine, Matsumoto, and 'Division of Cardiology, Toranomon Hospital, Tokyo, Japan.

Address for correspondence: Hiroshi Imamura, MD, First Department of Internal Medicine, Shinshu University School of Medicine, 3-1-1 Asahi, Matsumoto 390, Japan.

Received for publication May 22, 1996.

Accepted August 24, 1996. 
reperfusion therapy is beneficial only when it is performed within 6 hours of the onset of myocardial infarction, some studies have shown a reduction in mortality even when reperfusion therapy is performed 13 to 24 hours after the onset. ${ }^{5)}$ Furthermore, recent evidence suggests that reperfusion therapy may be beneficial even when it is performed days to weeks after the acute event. ${ }^{6-8)}$

On the other hand, whether or not restoration of antegrade coronary flow in the chronic phase of myocardial infarction improves prognosis remains controversial. Although percutaneous transluminal coronary angioplasty (PTCA) of obstructed coronary arteries is sometimes performed in patients with old myocardial infarction and single-vessel disease regardless of the presence of myocardial viability, there is no proof that restoration of antegrade flow improves the longterm prognosis in these patients. To assess the long-term efficacy of interventional therapy, it is important to clarify the prognosis of medically treated patients. Unlike in westcrn countries, ${ }^{9-11}$ only a few studies have been conducted in Japan on the long-tcrm prognosis of medically treated patients with coronary artery disease. ${ }^{12-16)}$ In addition, it is difficult to evaluate the natural course of coronary artery disease because of the increasing use of interventional therapy. We retrospectively investigated the long-term prognosis of patients with myocardial infarction with single-vessel disease and investigated the influence of the presence or absence of residual antegrade coronary blood flow in the chronic phase on prognosis. All patients included in this study were initially observed before the use of PTCA was introduced at our hospital, with most of them being seen before the Department of Cardiovascular Surgery was established.

\section{Methods}

Patients: We reviewed the records of all patients who underwent coronary angiography at Toranomon Hospital between September 1973 and February 1984 when PTCA was introduced at the hospital. Of the 3100 patients, 290 underwent coronary angiography 1 month or more following their first myocardial infarction, had single-vessel coronary artery disease, and received medical therapy for at least 1 year. Patients who received reperfusion therapy, those with lesions in the major coronary vessels due to aortitis or Kawasaki disease and those with valvular disease or cardiomyopathy were excluded from this study.

Coronary angiography and left ventriculography: Coronary angiography was performed using the Sones technique with a Cardiodiagnost apparatus (Philips, Best, Holland) and $35 \mathrm{~mm}$ cinefilm. Images were obtained in multiple projections before and after administration of sublingual nitroglycerin to obtain good visualization of the lesions and to assess the severity of stenosis. Antegrade flow in the infarct-related artery was graded in accordance with the criteria of the 
Thrombolysis in Myocardial Infarction (TIMI) study. ${ }^{17)}$ Patients were classified as having partial or complete antegrade perfusion (TIMI grade 2 or 3, group I, $n=184$ ) or no or minimal antegrade perfusion (TIMI grade 0 or 1, group II, $n=106)$. Left ventriculography was performed in the $30^{\circ}$ right anterior oblique and $60^{\circ}$ left anterior oblique projections and the left ventricular ejection fraction (LVEF) was calculated using the method of Kennedy.

Data acquisition: A questionnaire soliciting information about treatment and the dates and occurrence of cardiac events was either mailed to patients or completed by telephone. If the patient had died, the cause and the date of death were determined. Cardiac death was defined as sudden death, or death due to myocardial infarction or heart failure. The development of heart failure, the occurrence of acute myocardial infarction and the need for PTCA or coronary artery bypass grafting (CABG) were defined as nonfatal cardiac events. Acute myocardial infarctions that led to death within 1 month were regarded as cardiac deaths. The date of entry to the study was defined as the day on which the patient underwent coronary angiography. The follow-up period was completed on August 31, 1990.

Follow-up data were available for $262(90.3 \%)$ of 290 patients $(165 / 184$ in group I and 97/106 in group II), including 256 men and 6 women with a mean age of $52.3 \pm 9.8$ years. The mean follow-up period was $117.0 \pm 39.8$ months $(9.8$ years). There were no significant differences in baseline characteristics between groups, although the LVEF tended to be lower in group II (Table I).

Statistical analysis: Data are the mean \pm standard deviation. Group differences at baseline were assessed by the chi-square test for discrete variables and by Wilcoxon's test for continuous variables. Cumulative survival curves for cardiac death and for cardiac events were generated according to the Kaplan-Meier method. Deaths from noncardiac causes were classified as dropouts. Differences in survival rates were assessed by the generalized Wilcoxon test for 2 groups or by

Table 1. Patient Characteristics

\begin{tabular}{lcc}
\hline & $\begin{array}{c}\text { Group I } \\
(n=165)\end{array}$ & $\begin{array}{c}\text { Group II } \\
(n=97)\end{array}$ \\
\hline Age (yr) & $51.8 \pm 10.3$ & $53.2 \pm 8.9$ \\
Male sex $\%$ ) & $162(98.2)$ & $94(96.9)$ \\
Infarct-related artery (\%) & & \\
$\quad$ LAD & $110(66.7)$ & $67(69.1)$ \\
proximal LAD & $61(37.0)$ & $44(45.4)$ \\
LCx & $18(10.9)$ & $7(7.2)$ \\
RCA & $37(22.4)$ & $23(23.7)$ \\
LVEF (\%) & $61.3 \pm 16.3$ & $57.5 \pm 17.0$ \\
Months from MI to catheterization (median) & 3.8 & 4 \\
\hline
\end{tabular}

$\mathrm{LAD}=$ left anterior descending artery; $\mathrm{LCx}=$ left circumflex artery; $\mathrm{RCA}=$ right coronary artery; LVEF = left ventricular ejection fraction; $\mathrm{MI}=$ myocardial infarction. 
the log-rank test for more than two groups. A $p$ value $<0.05$ was considered significant.

\section{Results}

Prognosis: The overall survival rate was $95.7 \%$ at 5 years and $91.4 \%$ at 10 years. There was no significant difference in survival rates between group I (5year, 96.9\%; 10-year, 90.7\%) and group II (93.8\%; 92.7\%) (Figure 1). The overall 5-year and the 10-year event-free survival rates were $91.4 \%$ and $77.9 \%$, respectively. There was no significant difference in the event-free survival rate between group I (5-year, 92.6\%; 10-year, 79.7\%) and group II $(89.5 \% ; 74.8 \%$ ) (Figure 2). Similarly, there was no significant difference in the survival rate of patients free of heart failure and myocardial infarction between group I (5-year, $95.1 \%$; 10-year, 88.3\%) and group II $(91.6 \% ; 86.9 \%)$ (Figure 3).

Of the 23 cardiac deaths in the overall patient population, about half were due to sudden death, and half to acute myocardial infarction (Table II). There was no significant difference in the cause of death or in the rate of nonfatal cardiac events between groups, although CABG tended to be more frequent in group II than in group I. Of the 6 nonfatal myocardial infarctions, one was due to occlusion of the same site involved in the initial myocardial infarction (Table III). Both the first and second infarctions were attributed to coronary vasospasm in that patient from findings in emergent coronary angiography and his clinical course. Subsequent nonfatal myocardial infarctions were due to occlusion of coronary arteries other than that involved in the initial infarction in 4 patients. The target site of PTCA was an artery other than the artery involved in the initial myocardial infarction in 5 patients in whom PTCA was performed due to

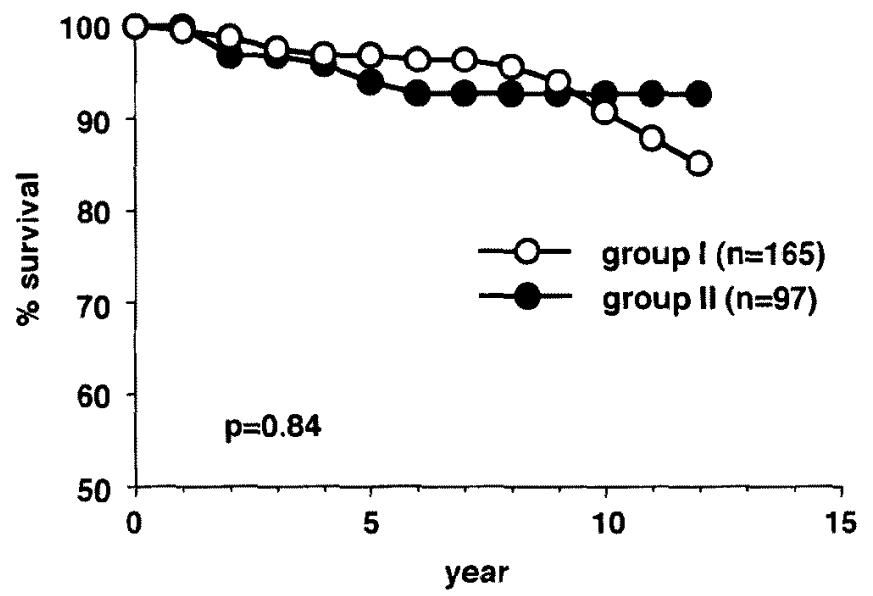

Figure 1. Cumulative survival curves in patients with (group I, open circles) and without (group II, closed circles) antegrade coronary blood flow. 


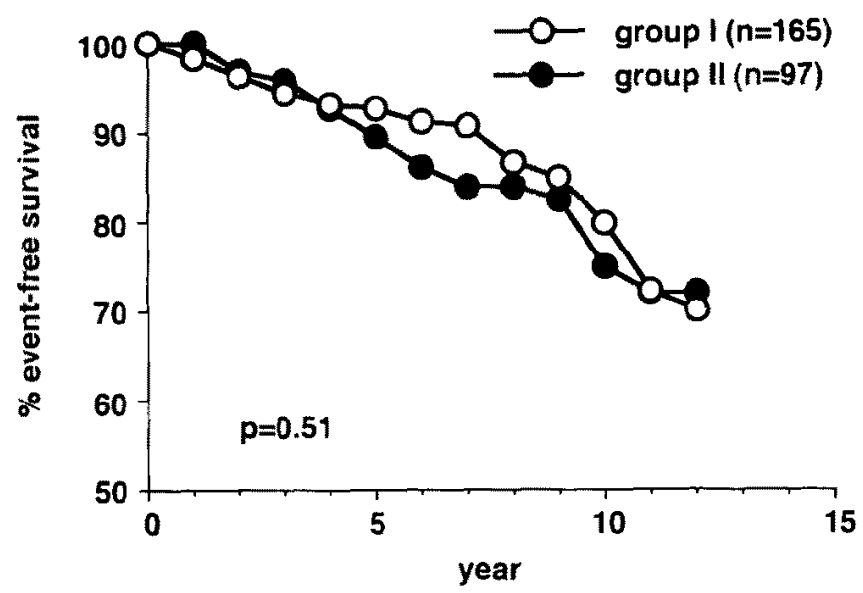

Figure 2. Cardiac event-free survival in patients with (group 1, open circles) and without (group II, closed circles) antegrade coronary blood flow. Cardiac events include heart failure, myocardial infarction, PTCA and CABG.

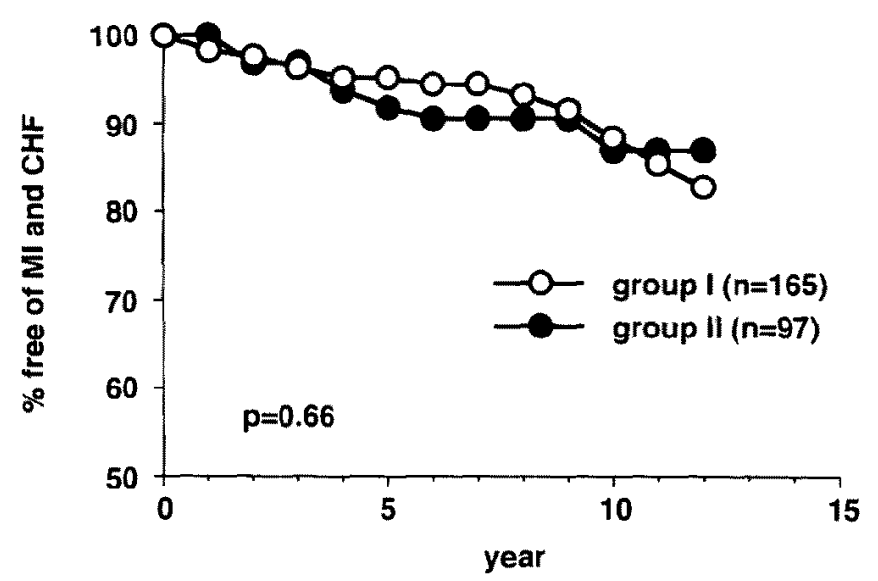

Figure 3. The percent survival in patients free of heart failure and myocardial infarction in group I (open circles) and group II (closed circles).

unstable angina. PTCA was performed at the same site as the infarct-related artery of the initial myocardial infarction in 3 patients who had stable angina prior to PTCA. Of 22 patients who underwent CABG, data about the surgery were available in 14 patients. In these 14 patients, 9 had double-vessel disease at the time of the surgery, 3 had triple-vessel disease, and 2 had left main coronary artery disease; none had single-vessel disease at the time of CABG.

\section{Influence of the severity of $\mathrm{LV}$ dysfunction, the infarct-related artery and} age: Because LV function has been proven to strongly influence the prognosis of patients with coronary artery disease, ${ }^{9,18)}$ we analyzed the prognosis of the entire group patients according to their LV function (Figure 4). The LVEF was 
Table II. Deaths and Nonfatal Cardiac Events

\begin{tabular}{|c|c|c|c|}
\hline & $\begin{array}{l}\text { Group I } \\
(n=165)\end{array}$ & $\begin{array}{c}\text { Group II } \\
(n=97)\end{array}$ & $\begin{array}{c}\text { Total } \\
(n=262)\end{array}$ \\
\hline \multicolumn{4}{|l|}{ Cardiac deaths $(\%)$} \\
\hline Total & $16(9.7)$ & $7(7.2)$ & $23(8.8)$ \\
\hline Sudden death & $8(4.8)$ & $3(3.1)$ & $11(4.2)$ \\
\hline MI & $7(4.2)$ & $4(4.1)$ & $11(4.2)$ \\
\hline Heart failure & $1(0.6)$ & 0 & $1(0.4)$ \\
\hline \multicolumn{4}{|c|}{ Nonfatal cardiac events $(\%)$} \\
\hline Total & $22(13.3)$ & $15(15.5)$ & $37(14.1)$ \\
\hline $\mathrm{MI}$ & $3(1.8)$ & $3(3.1)$ & $6(2.3)$ \\
\hline Heart failure & $2(1.2)$ & $3(3.1)$ & $5(1.9)$ \\
\hline PTCA & $6(3.6)$ & $4(4.1)$ & $10(3.8)$ \\
\hline CABG & $12(7.3)$ & $10(10.3)$ & $22(8.4)$ \\
\hline Noncardiac deaths $(\%)$ & $11(6.7)$ & $5(5.2)$ & $16(6.1)$ \\
\hline
\end{tabular}

Total nonfatal cardiac events are the number of patients. $\mathrm{MI}=$ myocardial infarction; PTCA = percutaneous transluminal coronary angioplasty; $\mathrm{CABG}=$ coronary artery bypass grafting.

Table III. Infarct-related Arteries in Subsequent Nonfatal MIs and Target Sites of PTCA during Follow-up

\begin{tabular}{lcc}
\hline & $\begin{array}{c}\text { IRA of subsequent MI } \\
(n=6)\end{array}$ & $\begin{array}{c}\text { Target site of PTCA } \\
(n=10)\end{array}$ \\
\hline Same as initial MI & 1 & 3 \\
Different from initial MI & 4 & 5 \\
Unknown & 1 & 2 \\
\hline
\end{tabular}

IRA = infarct-related artery; $\mathrm{MI}=$ myocardial infarction; PTCA = percutaneous transluminal coronary angioplasty.

more than $60 \%$ in 144 patients (97 in group I, 47 in group II), 40 to $60 \%$ in 91 patients (57 in group I, 34 in group II), and less than $40 \%$ in 25 patients (10 in group I, 15 in group II). The 10-year survival rates of patients with LVEFs of $>60 \%, 40$ to $60 \%$ and $<40 \%$ were $94.9 \%, 90.6 \%$ and $74.8 \%$, respectively. Thus, the survival rate decreased significantly as the severity of $L V$ dysfunction increased. Similarly, the survival rate in patients free of heart failure and myocardial infarction decreased as the severity of $\mathrm{LV}$ dysfunction increased: 10-year survival rates for patients with LVEFs of $>60 \%, 40$ to $60 \%$ and $<40 \%$ were $91.2 \%, 85.6 \%$ and $74.8 \%$, respectively $(p=0.03)$. Among patients with an LVEF less than $40 \%$, there was no significant difference in the survival rate between group I (5-year, $80.0 \% ; 10$-year, 68.6\%) and group II $(86.7 \%$; 79.4\%) (Figure 5).

The 10-year survival rate tended to be influenced by the location of the infarct-related artery as follows: LAD (89.9\%), RCA (92.6\%), and LCx $(100 \%)$, although this was not statistically significant (Figure 6). Lesions were present in the proximal segment of the LAD in 105 of the 262 patients (61 in group I, 44 in group II). The 5-year and 10-year survival rates in patients with proximal LAD 


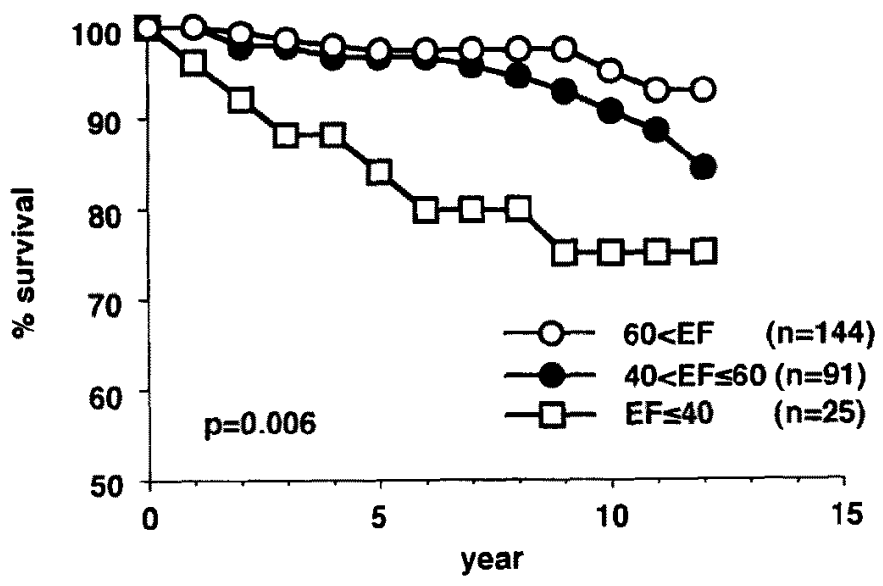

Figure 4. Cumulative survival curves according to left ventricular function. $\mathrm{EF}=$ ejection fraction.

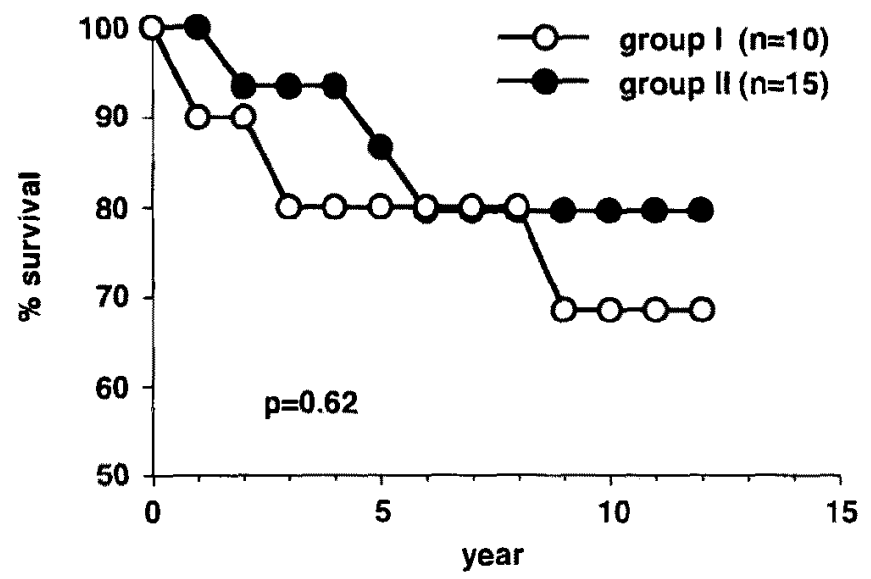

Figure 5. Cumulative survival curves in group I (open circles) and group II (closed circles) in the subset of patients with poor LV function ( $L V E F<40$ ).

disease were $95.1 \%$ and $89.8 \%$, respectively, which werc slightly lower than survival rates in the 157 patients without proximal LAD disease $(96.1 \%$ and $92.9 \%$, respectively). There was no significant difference in survival rates between group I (5-year, 98.3\%; 10-year, 89.4\%) and group II $(90.8 \% ; 90.8 \%)$ patients with lesions in the proximal segment of the LAD (Figure 7). Survival rates did not differ significantly between group I and group II subsets of patients with lesions of the RCA, the LCx or the distal segment of LAD.

We also compared the prognosis according to age. The survival rates were significantly lower in patients $\geq 55$ years of age $(n=113)(5$-year, $92.8 \%$; 10-year, $83.0 \%)$ than in patients $<55$ years of age $(98.0 \% ; 97.0 \%)(p=0.004)$. Survival 


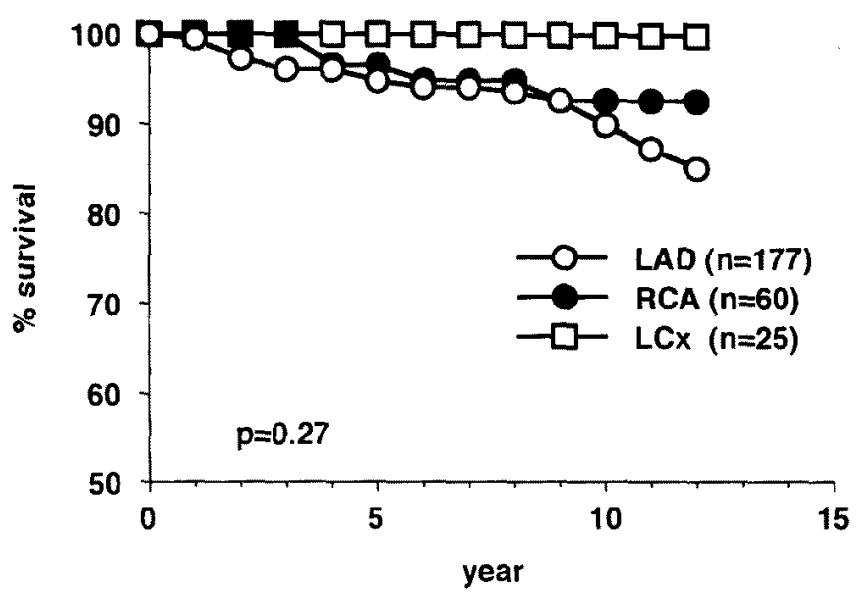

Figure 6. Cumulative survival curves according to the infarct-related artery. $\mathrm{LAD}=$ left anterior descending artery; $\mathrm{RCA}=$ right coronary artery; $\mathrm{LCx}=$ left circumflex artery.

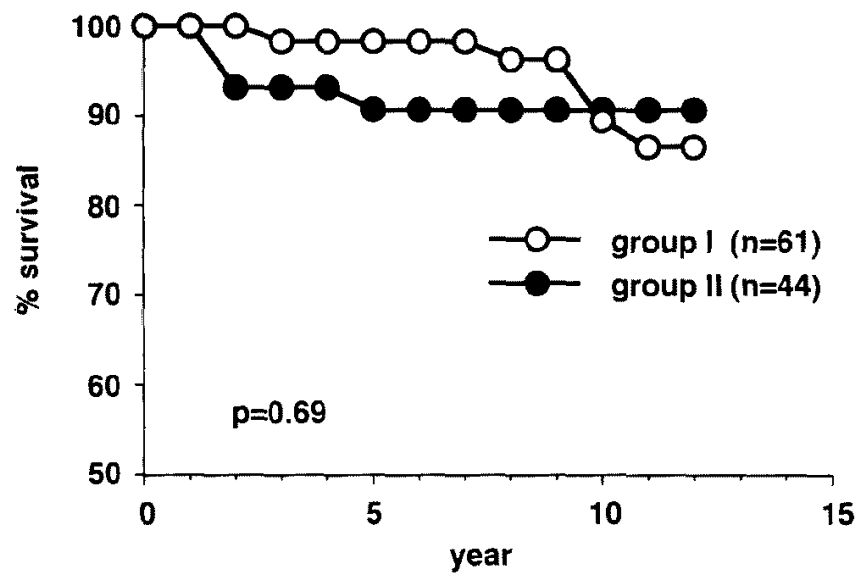

Figure 7. Cumulative survival curves in group I (open circles) and group II (closed circles) in the subset of patients with diseased vessel of proximal segment of the left anterior descending artery.

rates were similar in group I and group II patients classified according to age.

\section{Discussion}

This study demonstrated that the presence or absence of residual antegrade coronary flow in the chronic phase of myocardial infarction did not influence the prognosis of patients with single-vessel disease. Survival and cardiac event-free rates during the 10-year follow-up period were similar in patients with and without antegrade flow. Survival and cardiac event-free rates of patients with and 
without antegrade flow were similar within all subsets of patients, including patients with poor LV function, proximal LAD disease and older age.

About half of the 23 cardiac deaths that occurred in the overall study population were due to re-infarction and half to sudden death, which was probably due to acute myocardial infarction or arrhythmia. There was only 1 death due to heart failure. Furthermore, the site of occlusion was different from the infarct-related artery of the initial myocardial infarction in the majority of patients who subsequently experienced nonfatal myocardial infarctions. The target sites of PTCA performed due to unstable angina were different from the infarctrelated artery of the initial myocardial infarction in all cases. CABG was performed to treat multivessel disease or left main coronary artery disease. These findings suggest that subsequent cardiac events were related to the progression of atherosclerosis in previously nonstenotic coronary arteries in the majority of patients with single-vessel disease. That seems to be the major reason why the presence of antegrade coronary flow did not significantly influence the prognosis.

Cigarroa et al ${ }^{199}$ reported that the long-term survival was significantly better in survivors of myocardial infarction with single-vessel disease with antegrade flow in the infarct-related artery about 1 month after the onset compared with patients whose infarct-related artery remained occluded. Similar findings were reported by Trappe et al. ${ }^{201}$ Thus, the patency of the infarct-related artery days to weeks after the onset has been shown to markedly influence the long-term prognosis of survivors of myocardial infarction. In these previous studies, patients were studied within 1 month of the onset of myocardial infarction, whereas we studied patients in the chronic phase (median: 4 months after the onset of myocardial infarction). Thus, patients in our study were those who survived their acute or subacute phase of myocardial infarction and some patients without antegrade coronary flow may have died before initiation of the present study.

Previous studies have shown that restoration of antegrade coronary flow in patients with acute myocardial infarction improves both short-term ${ }^{4,5)}$ and longterm survival. ${ }^{21)}$ Recent evidence suggests that the restoration of antegrade flow may be beneficial even if it is achieved days to weeks after the acute event. ${ }^{68}$ The improved survival may be related to mechanisms other than the beneficial effect of restoration of antegrade flow on LV function, including reductions in ventricular remodeling ${ }^{22)}$ and the incidence of arrhythmias, ${ }^{23,24}$ and the establishment of collaterals to other areas that would be beneficial in the event of future coronary artery occlusion. ${ }^{25,26)}$ However, the effect of restoration of antegrade coronary flow in the chronic phase of myocardial infarction on prognosis has not been determined. PTCA is sometimes performed to treat chronic coronary obstruction in the absence of myocardial viability in patients with myocardial infarction and single-vessel disease on the assumption that restoration of antegrade coronary 
flow improves prognosis. However, the results of the present study suggest that such a procedure performed during the chronic phase of myocardial infarction may have only a small benefit, if any, on long-term prognosis in patients with single-vessel disease. The mechanical restoration of antegrade flow by PTCA or $\mathrm{CABG}$ is neither inexpensive nor free of morbidity and mortality. Therefore, a prospective, randomized study is needed to assess the influence of these procedures on prognosis.

The present study confirmed that the extent of LV dysfunction is an important determinant of prognosis, as previous studies ${ }^{9,18)}$ have indicated. Survival rates as well as survival rates free of heart failure and myocardial infarction decreased significantly as the severity of $\mathrm{LV}$ function increased. The 4-year survival rates of patients with single-vessel disease and LVEFs of 50 to $100 \%, 35$ to $49 \%$ and $<35 \%$ were $95 \%, 91 \%$ and $74 \%$, respectively, in the Coronary Artery Surgery Study (CASS) ${ }^{18)}$ In the present study, patient age was also a determinant of survival, even when noncardiac deaths were excluded.

The long-term prognosis of medically treated patients with myocardial infarction and single-vessel disease was good in the present study. The 5-year and 10-year survival rates of medically treated patients with single-vessel disease were $93 \%$ and $82 \%$, respectively, in the CASS $^{11)}$ and $88 \%$ and $71 \%$, respectively, in the Veterans Administration study. ${ }^{9)}$ Thus, the prognosis of Japanese patients with coronary artery disease may be more favorable than that of patients in Western countries.

Our study has certain limitations. First, because it was a retrospective assessment of patients with myocardial infarction and single-vessel disease, there may have been some bias in the selection of patients. Furthermore, presence or absence of myocardial viability was not evaluated. However, all the patients included in this study were initially seen before the introduction of PTCA at our hospital, and most of them were seen before the establishment of the Department of Cardiovascular Surgery. Some patients would have been candidates for PTCA or CABG. Thus, there was a marked variation in the severity of disease. Second, although this study demonstrated that LVEF significantly influenced the prognosis, determinants of LVEF were unknown. They could not be clarified because not all patients were treated in our hospital in their acute phase of myocardial infarction. Patency of the infarct-related artery seemed to be one of the determinants of LVEF because group I tended to have higher LVEF. Third, the present study included only patients who had chronic stable single-vessel coronary artery disease. It is possible that we found no significant difference in survival between subgroups of patients because survival is already excellent in this group of patients. ${ }^{27)}$ Fourth, coronary risk factors were not evaluated in this study. Thus, it is possible that some difference in risk factors influenced the prognosis of two 
groups.

In conclusion, the presence or absence of residual antegrade coronary blood flow in the chronic phase had no significant influence on the long-term prognosis of medically treated patients with myocardial infarction with single-vessel disease. Subsequent cardiac mortality and morbidity were related to the progression in atherosclerosis of coronary arteries other than the infarct-related artery in most patients. LV function and age significantly influenced survival.

\section{RefERences}

1. The TIMI Study Group. The Thrombolysis in Myocardial Infarction (TIMI) trial. Phase 1 findings. N Engl J Med 1985; 312: 932-6.

2. Hartzler GO, Rutherford BD, McConahay DR. Percutaneous transluminal coronary angioplasty: application for acute myocardial infarction. Am J Cardiol 1984; 53: 17C-21C.

3. Topol EJ, Califf RM, George BS, et al. A randomized trial of immediate versus delayed elective angioplasty after intravenous tissue plasminogen activator in acute myocardial infarction. $\mathrm{N}$ Engl J Med 1987; $317: 581-8$.

4. Gruppo Italiano per lo Studio delia Streptochinasi nell' Infarto Miocardico (GISSI). Effectiveness of intravenous thrombolytic treatment in acute myocardial infarction. Lancet 1986; 1: 397-401.

5. ISIS-2 (Second International Study of Infarct Survival) Collaborative Group. Randomized trial of intravenous streptokinase, oral aspirin, both, or neither among 17,187 cases of suspected acute myocar* dial infarction: ISIS-2. Lancet 1988; 2: 349-360.

6. Ohman EM, Capiff RM, Topol EJ, et al. Consequence of reocclusion after successful reperfusion therapy in acute myocardial infarction. Circulation 1990; 82: 781-91.

7. Sabri MN, DiSciascio G, Cowlcy MJ, et al. Immediate and longuterm results of delayed recanalization of occluded acute myocardial infarction-related arteries using coronary angioplasty. Am J Cardiol 1992; 69: 575-8.

8. White HD, Cross DB, Elliot JM, Norris RM, Yee TW. Long-term prognostic importance of patency of the infarct-related coronary artery after thrombolytic therapy for acute myocardial infarction. Circulation 1994; 89: 61-7.

9. The Veterans Administration Coronary Artery Bypass Surgery Cooperative Study Group. Elevenyear survival in the Veterans Administration randomized trial of coronary bypass surgery for stable angina. N Engl J Med 1984; 311: 1333-9.

10. Varnauskas E, and the European Coronary Surgery Study Group. Twelve-year follow-up of survival in the Randomized European Coronary Surgery Study. N Engl J Med 1988; 319: 332-7.

11. Alderman EL, Bourassa MG, Cohen LS, et al. Ten-year follow-up of survival and myocardial infarction in the randomized Coronary Artery Surgery Study. Circulation 1990; 82: 1629-46.

12. Osugi J, Takatsu F. Prognosis of medically treated coronary artery disease; correlation with angiographic findings. Coronary 1984; 1: 186-92.

13. Chino M, Yoshino H, Tani M, et al. Prognosis of medically treated coronary artery disease. Nippon Naika Gakkai Zasshi 1987; 76: 1033-1038, (in Japanese).

14. Saito M, Fukami K, Hiramori K, et al, Long-term prognosis of patients with acute myocardial infarction; Is mortality and morbidity as low as the incidence of ischemic heart disease in Japan? Am Heart J 1987; 113: 891-7.

15. Hosoda $S$, Iino $T$, Yasuda $H$, et al. Long-term follow-up of medically treated patients with coronary artery disease. I. Incidence of major cardiac events and its risk factors in Japanese with coronary artery disease. Jpn Circ J 1990; 54: 231-40.

16. Nishiyama S, Kato K, Nakanishi S, Seki A, Yamaguchi H. Long-term prognosis in 990 medically treated Japanese patients with coronary artery disease. Jpn Heart J 1993; 34: 539-50.

17. Chesebro JH, Knatterud G, Roberts R, et al. Thrombolysis in Myocardial Infarction (TIMI) trial, 
Phase I: a comparison between intravenous tissuc plasminogen activator and intravenous streptokinase. Clinical findings through hospital discharge. Circulation 1987; 76: 142-54.

18. Mock MB, Ringqvist I, Fisher LD, et al. Survival of medically treated patients in the Coronary Artery Surgery Study (CASS) registry. Circulation 1982; 66: 562-8.

19. Cigarroa RG, Lange RA, Hillis LD. Prognosis after acute myocardial infarction in patients with and without residual anterograde coronary blood flow. Am J Cardiol 1989; 64: 155-60.

20. Trappe HJ, Lichtlen $P R$, Klein $H$, Wenzlaff $P$, Hartwig CA, Natural history of single vessel disease. Risk of sudden death in relation to coronary anatomy and arrhythmia profile. Eur Heart $\mathrm{J} \mathrm{1989;10:}$ $514-24$.

21. Dalen JE, Gore JM, Braunwald E, et al. Six and twelve-month follow-up of the phase I thrombolysis in myocardial infarction (TIMI) trial. Am J Cardiol 1988; 62: 179-85.

22. Hochman JS, Choo H. Limitation of myocardial infarct expansion by reperfusion independent of myocardial salvage. Circulation 1987; 75: 299-306.

23. Kersschot IE, Brugada P, Ramentol M, et al. Effects of early reperfusion in acute myocardial infarction on arrhythmias induced by programmed stimulation: a prospective, randomized study. J Am Coll Cardiol 1986; $7: 1234-42$.

24. Lange RA, Cigarroa RG, Wells PJ, Kremers MS, Hills LD. Influence of antegrade flow in the infarct artery on the incidence of late potentials after acute myocardial infarction. Am J Cardiol 1990; 65: 5548.

25. Dervan J, Briam DS, Cherniles J, Grossman W. Transluminal angioplasty of occluded coronary arteries: use of a movable guidewire system. Circulation 1983; 68: 776-84.

26. Nath A, DiSciascio G, Kelly KM, et al. Multivessel coronary angioplasty early after acute myocardial infarction. J Am Coll Cardiol 1990; 16: 545-50.

27. CASS Principal Investigators and their Associates. Myocardial infarction and mortality in the Coronary Artery Surgery Study (CASS) randomized trial. N Engl J Med 1984; 310: 750-8. 